\title{
Delayed recall of childhood sexual abuse memories and the awakening rise and diurnal pattern of cortisol
}

Citation for published version (APA):

Smeets, T., Geraerts, E. G., Jelicic, M., \& Merckelbach, H. L. G. J. (2007). Delayed recall of childhood sexual abuse memories and the awakening rise and diurnal pattern of cortisol. Psychiatry Research, 152, 197-204. https://doi.org/10.1016/j.psychres.2006.07.008

Document status and date:

Published: 01/01/2007

DOI:

10.1016/j.psychres.2006.07.008

Document Version:

Publisher's PDF, also known as Version of record

\section{Please check the document version of this publication:}

- A submitted manuscript is the version of the article upon submission and before peer-review. There can be important differences between the submitted version and the official published version of record.

People interested in the research are advised to contact the author for the final version of the publication, or visit the DOI to the publisher's website.

- The final author version and the galley proof are versions of the publication after peer review.

- The final published version features the final layout of the paper including the volume, issue and page numbers.

Link to publication

\footnotetext{
General rights rights.

- You may freely distribute the URL identifying the publication in the public portal. please follow below link for the End User Agreement:

www.umlib.nl/taverne-license

Take down policy

If you believe that this document breaches copyright please contact us at:

repository@maastrichtuniversity.nl

providing details and we will investigate your claim.
}

Copyright and moral rights for the publications made accessible in the public portal are retained by the authors and/or other copyright owners and it is a condition of accessing publications that users recognise and abide by the legal requirements associated with these

- Users may download and print one copy of any publication from the public portal for the purpose of private study or research.

- You may not further distribute the material or use it for any profit-making activity or commercial gain

If the publication is distributed under the terms of Article $25 \mathrm{fa}$ of the Dutch Copyright Act, indicated by the "Taverne" license above, 
Provided for non-commercial research and education use. Not for reproduction, distribution or commercial use.

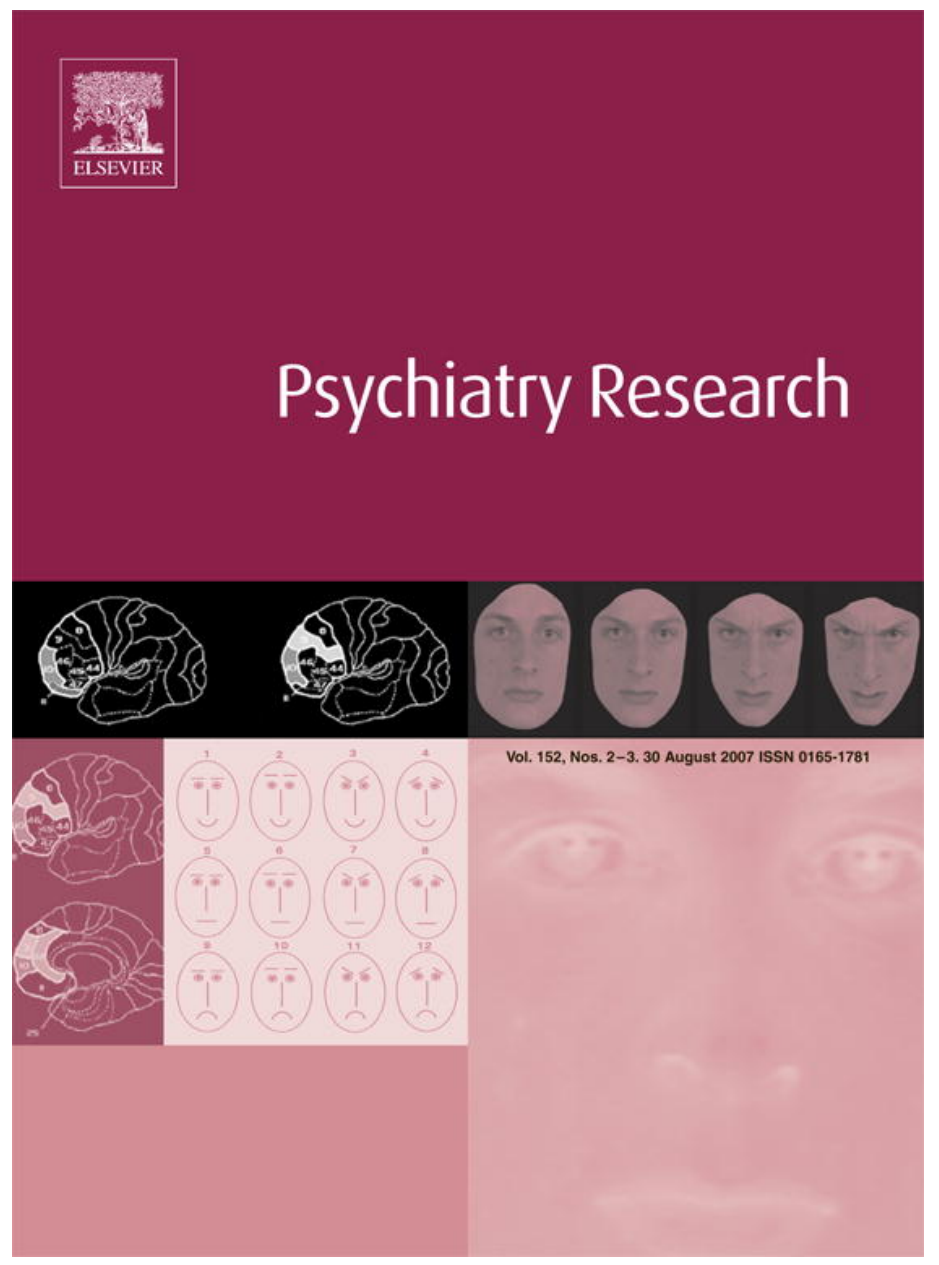

This article was published in an Elsevier journal. The attached copy

is furnished to the author for non-commercial research and education use, including for instruction at the author's institution, sharing with colleagues and providing to institution administration.

Other uses, including reproduction and distribution, or selling or licensing copies, or posting to personal, institutional or third party websites are prohibited.

In most cases authors are permitted to post their version of the article (e.g. in Word or Tex form) to their personal website or institutional repository. Authors requiring further information regarding Elsevier's archiving and manuscript policies are encouraged to visit: 


\title{
Delayed recall of childhood sexual abuse memories and the awakening rise and diurnal pattern of cortisol
}

\author{
Tom Smeets *, Elke Geraerts, Marko Jelicic, Harald Merckelbach \\ Department of Experimental Psychology, Maastricht University, The Netherlands
}

Received 9 February 2006; received in revised form 6 June 2006; accepted 26 July 2006

\begin{abstract}
Traumatic stress associated with childhood sexual abuse (CSA) may result in chronic alterations of stress-sensitive neurochemical systems (e.g., the hypothalamic-pituitary-adrenal axis and sympathetic-adrenal medullary activity). Some authors have suggested that these alterations might help explain why some individuals, after a period of inability to remember, demonstrate delayed recall of CSA memories (i.e., "recovered" memories). The present study is the first study that explored morning cortisol responses and circadian cortisol profiles among women with recovered $(n=7)$, repressed $(n=8)$, or continuous $(n=6)$ memories of CSA and women without a history of CSA $(n=9)$. Although there were group differences in current depression and post-traumatic stress symptoms, we found no differences in cortisol awakening response or daytime profile between women reporting recovered, repressed, or continuous memories of CSA as compared to women without a history of CSA. Implications for neurobiological models intended to explain the delayed recall of CSA are discussed.
\end{abstract}

(C) 2006 Elsevier Ireland Ltd. All rights reserved.

Keywords: glucocorticoids; cortisol; recovered memory; repressed memory; CSA

\section{Introduction}

Reports of individuals suddenly recovering previously inaccessible memories of past traumas, in particular experiences of childhood sexual abuse, have generated heated debate. Many clinicians (e.g., Scheflin and Brown, 1996; Alpert et al., 1998) believe that the traumatic nature of childhood sexual abuse (CSA) can render its victims amnesic for CSA episodes. They assume that in repressed and recovered memory cases special mechanisms termed repression or dissociation produce periods of psychogenic (i.e., dissociative) amnesia. Other authors, however, have questioned the accuracy of repressed and recovered

\footnotetext{
* Corresponding author. Tel.: +31 43388 4506; fax: +31 433884196. E-mail address: tom.smeets@psychology.unimaas.nl (T. Smeets).
}

memories. They argue that there is no sound evidence for special mechanisms linking trauma to dissociative amnesia (e.g., Pope et al., 1998; Roediger and Bergman, 1998; McNally, 2003; Loftus, 2004; Kihlstrom, in press).

Some authors (e.g., Howe, 1998; Bremner, 2001) have argued that biological factors rather than poorly defined mechanisms like repression underlie the loss and, perhaps, the recovery of traumatic memories. These factors would involve stress-sensitive neuroendocrine systems and their products, such as norepinephrine and cortisol. Authors stressing the importance of these factors reason that childhood abuse results in permanent effects on brain systems and circuits that mediate the stress response. Specifically, Bremner (2003) maintains that early stress has lasting effects on the hypothalamicpituitary-adrenal (HPA) axis. For example, an early 
stressor like maternal deprivation can result in increased glucocorticoid responses to subsequent stressors (Stanton et al., 1988). Additionally, at least in nonhuman primates damaging early stressors can result in lasting effects on behaviors and elevated levels of corticotrophin releasing factor in cerebrospinal fluid. Taken together, these and other reports suggest that "[...] early adverse experience permanently affects the HPA axis" (Bremner, 2003, p. 272).

Taking this line of reasoning one step further, Bremner (2001) seems to postulate that altered cortisol levels following trauma exposure may account for the delayed recovery of CSA memories. There have indeed been reports of delayed recall of verbal material due to stress-induced cortisol elevations (e.g., Elzinga et al., 2005). Accordingly, long-term alterations in neuroendocrine systems such as the HPA axis may modulate the functioning of certain brain regions such as the hippocampus, the amygdala, and prefrontal cortex. Particularly sensitive to the effects of stress is the hippocampus, a brain area crucial to learning and memory. As early stressors (e.g., CSA) may permanently alter HPA axis functioning, this in turn might exert damaging effects on the hippocampus. By this argument, delayed recall of CSA is related to hippocampal dependent memory deficiencies that result from the long-lasting effects of childhood abuse on the HPA axis functioning.

If true, cortisol levels might be expected to differ in people who claim to have repressed or recovered CSA memories from people who have always remembered being abused, or for that matter from people without a history of CSA. Typically, activity of the HPA axis follows a circadian rhythm. In the morning, a rapid and acute increase in cortisol (i.e., the primary glucocorticoid secreted by the adrenal cortex) levels can generally be observed, with a peak occurring at about 30 min after awakening (Pruessner et al., 1997; Wüst et al., 2000a,b). Thereafter, cortisol levels continually decrease during the remainder of the day. The awakening rise in cortisol is known to be affected by a host of factors including, for example, burnout (e.g., Pruessner et al., 1999), vital exhaustion (e.g., Nicolson and van Diest, 2000), chronic stress (e.g., Wüst et al., 2000a,b; Steptoe et al., 2003), and genetic predisposition (e.g., Wüst et al., 2000a,b). Moreover, larger morning responses are typically found during the week than in weekends, apparently reflecting higher stress on work days (e.g., Kunz-Ebrecht et al., 2004).

So far, no study has investigated cortisol secretion in individuals reporting recovered, repressed, or continuous CSA memories, compared to people with no history of CSA. The aim of the present study was therefore to assess whether women with recovered, repressed, or continuous CSA memories or without a CSA history differ in two cortisol secretion parameters, namely their response to morning awakening and their diurnal pattern. One would predict differences in the circadian rhythm of cortisol secretion between these groups if massive bursts of glucocorticoids in response to CSA can, indeed, initiate neurochemical alterations that undermine memory (e.g., Bremner et al., 1996). More specifically, one would expect heightened morning and diurnal cortisol levels in recovered and repressed memory patients compared to those in continuous memory patients and non-traumatized controls. On the other hand, a recent study suggests that lowered rather than raised cortisol levels in response to awakening are linked to a total inaccessibility of memories (e.g., Wolf et al., 2005). Based on that study, one would expect that those individuals who claim to have repressed their CSA memories show deregulations in morning cortisol responses. It should be noted though that patients suffering from posttraumatic stress disorder (PTSD) are characterized by lower blunted responses to awakening and lower diurnal cortisol levels (e.g., Yehuda, 2002). Therefore, PTSD symptomatology should be taken into account when studying cortisol levels in women with a history of CSA, especially given reports of memory deficits in women with CSA related PTSD (e.g., Bremner et al., 2004).

\section{Methods}

\subsection{Participants}

Participants were recruited through advertisements in local newspapers as part of an ongoing project on CSA memories and psychopathology (e.g., Geraerts et al., 2005, 2006). After having given informed consent, all women underwent a semi-structured memory interview performed by E.G.. On the basis of this interview, participants were classified as belonging to one of four groups. The first group consisted of women who said that after a period of having been unable to remember CSA episodes, they had subsequently recalled memories of CSA (i.e., recovered memory group). Women with this type of CSA memories had either recovered their memories during psychiatric treatment or after having been exposed to certain cues (e.g., a friend who told about CSA experiences, the birth of their own child). Women in the second group firmly believed they had been sexually abused as a child but had no memories of the abuse (i.e., the repressed memory group). They reported a wide range of symptoms that they thought were indicative of a CSA history (e.g., relationship problems, depressive symptoms, 
and eating disorders). Women who reported that they had always remembered being abused as a child were included in the third (i.e., continuous memory) group, while the fourth (i.e., control) group consisted of women who said they had no history of childhood or adulthood sexual abuse. As we were unable to verify whether or not participants had experienced CSA events, the terms "recovered", "repressed", "continuous", and "no CSA background" describe the belief that participants had about their own history.

None of the participants in the recovered, repressed, or continuous group self-reportedly stated that they had experienced (potentially) traumatic events in their lives other than CSA. Participants in the control group all indicated that they were free of having experienced traumatic events in their lives. Only participants who had a normal body mass index (BMI) were included in this study.

Exclusion criteria included being (post-)menopausal and suffering from chronic fatigue or a current psychotic disorder. None of the participants met criteria for current or lifetime psychiatric disorders including, for example, major depressive disorder (MDD). Ten participants were excluded from analysis because they suffered from endocrine disorders (e.g., adrenal insufficiency, thyroid disease; $n=3$ ), serious medical diseases (e.g., fibromyalgia; $n=3$ ), or were on medications known to affect the HPA axis (e.g., antidepressants, synthetic corticosteroids; $n=4$ ). This resulted in a group of 30 women suitable for analyses including 7 recovered, 8 repressed, and 6 continuous memory patients, and 9 non-abused controls. All test protocols were approved by the standing ethical committee of the Faculty of Psychology, Maastricht University.

\subsection{Materials}

The Dissociative Experiences Scale (DES; Bernstein and Putnam, 1986; Cronbach's $\alpha=0.92$ ) is a widely used self-report instrument containing 28 items describing dissociative phenomena, such as feelings of derealization, depersonalization, disturbances in identity, memory, awareness, and cognition. Participants indicate on 100$\mathrm{mm}$ Visual Analogue Scales (anchors: not at all and very much) the frequency with which they experience the phenomena described by each item. Scores on the individual items are averaged to obtain a mean DES score, with higher scores indicating a higher frequency of dissociative symptoms. The psychometric qualities of the DES are well established (e.g., Van IJzendoorn and Schuengel, 1996).

The Beck Depression Inventory (BDI; Beck et al., $1961 ; \alpha=0.81)$ is a widely-used and extensively validated self-report scale designed to evaluate depressive symptoms in clinical as well as in research settings (for a review, see Beck et al., 1988). The BDI comprises 21 items scored on 4-point scales (anchors vary with items). Total BDI scores range from 0 to 63 , with higher values representing more depressive symptoms.

The Posttraumatic Stress Symptom Scale-Self-Report Version (PSS-SR; Foa et al., 1993; $\alpha=0.92$ ) is a selfreport measure comprising 17 items corresponding to the re-experiencing, avoidance, and arousal symptoms of PTSD. Participants rate the frequency of each item on 4point scales ranging from 0 (not at all or only one time) to 3 (five or more times a week/almost always). A total score can be obtained by summing across items. Psychometric evidence that supports the PSS-SR as a screening tool for PTSS can be found in Wohlfarth, van den Brink, Winkel, and ter Smitten (2003).

\subsection{Procedure}

After having given informed consent, participants were contacted by mail and provided with questionnaires and cortisol sampling devices (Salivettes; Sarstedt ${ }^{\circledR}$, Nümbrecht, Germany), as well as detailed instructions on how and when to collect all data. Participants collected the saliva samples at home on two consecutive weekdays. Cortisol awakening response and diurnal pattern were assessed as follows. For the awakening rise, all participants obtained the first saliva sample immediately upon awakening, followed by additional samples collected $15 \mathrm{~min}, 30 \mathrm{~min}$, and $45 \mathrm{~min}$ thereafter (for a rationale, see Pruessner et al., 1997). The diurnal pattern of cortisol secretion was characterized by saliva samples collected at 09.00 h, $11.00 \mathrm{~h}, 15.00 \mathrm{~h}$, and $20.00 \mathrm{~h}$. Participants were instructed to closely follow the guidelines for data collection and were asked to record time of awakening and times of saliva sampling. Participants were also asked to rate the quality of their night's sleep on a $100 \mathrm{~mm}$ VAS (anchors: $0=$ very bad; $100=$ very good; with 50 being the quality of a typical night's sleep). After collection of all saliva samples, participants returned the completed forms and sampling devices in a self-addressed envelope.

Upon return, uncentrifuged saliva samples were stored at $-40^{\circ}$ Celsius. Salivary free cortisol levels were determined in duplicate by direct radioimmunoassay (RIA; University of Liège, Belgium), including a competition reaction between ${ }^{125}$ iodohistamine-cortisol and anti-cortisol serum made against the 3-CMO-BSA conjugate. After overnight incubation at $4^{\circ}$ Celsius of $50 \mu$ of saliva, separation of free and antibody-bound ${ }^{125}$ iodohistaminecortisol was performed via a conventional 'second antibody' method. This way, the lower detection limit of the assay was $0.1 \mathrm{nmol} / \mathrm{l}$. Mean intra- and inter-assay coefficients of variation were less than $4.3 \%$ and $9 \%$, 
respectively. Cortisol levels for each sampling time were averaged for the 2 consecutive days. However, cortisol samples that according to self-report deviated more than $3 \mathrm{~min}$ from the standard time of measurement for the morning response or that deviated more than $15 \mathrm{~min}$ from the standard times for the daytime profile were discarded from further analysis. This was the case for 15 (3.1\%) of all measurements. In these cases, cortisol data reflect only one data point instead of the average across 2 days.

\subsection{Statistical analyses}

Group differences in scores on the psychometric instruments were evaluated with univariate Analyses of Variance (ANOVA's) and follow-up $t$-tests. Cortisol data were examined for outliers, but none were identified. To normalize distributions, cortisol levels were subjected to natural $\log$ transformation before analyses. A 4 (group: recovered vs. repressed vs. continuous vs. controls $) \times 4$ (time: wake-up vs. $t+15$ vs. $t+30$ vs. $t+45$ ) ANOVA was used to analyze the awakening rise, with time as the repeated measure factor. Similarly, diurnal patterns were analyzed using a 4 (group) $\times 4$ (time: $09.00 \mathrm{~h}$ vs. $11.00 \mathrm{~h}$ vs. $15.00 \mathrm{~h}$ vs. $20.00 \mathrm{~h}$ ) ANOVA. Additionally, univariate ANOVA's were used to test group differences in the cortisol Area Under the Curve (AUC; see Pruessner et al., 1997, 2003) with respect to increase (AUCi) for morning responses. Likewise, the Awakening Cortisol Response (ACR) was computed as $[(t+30)-($ wake-up) $]$ (see, for example, Clow et al., 2004). Following Sephton et al. (2000) and Weissbecker et al. (2006), we quantified the diurnal cortisol slope ( $($ ) by estimating how each participant fit the normal descending profile. To this end, a series of multiple regressions with cortisol values regressed upon the time of collection (i.e., cortisol sample) individually for each participant. Larger $\beta$ values represent flatter slopes and, thus, slower declines in cortisol. Steeper slopes (smaller $\beta$ 's), on the other hand, indicate that cortisol decreases more rapidly. Finally, we computed Daily Average Cortisol (DAC; Gunnar et al., 2001; Nicolson, 2004) by first standardizing cortisol measures over all participants at each sampling time and then averaging these Z-scores for each participant. Pearson product-moment correlations (two-tailed) were used to examine whether questionnaire scores (DES, BDI, and PSS-SR) were related to cortisol awakening responses (AUCi and ACR) and diurnal cortisol values (DAC and $\beta$ 's). Greenhouse-Geisser corrected $P$-values are reported when sphericity assumptions were violated. Partial Eta squared $\left(\eta_{\mathrm{p}}^{2}\right)$ is provided as a measure of effect size. Unless otherwise specified, alpha was set at 0.05 and adjusted (Bonferroni) for multiple comparisons where necessary.

\section{Results}

\subsection{Psychometric data}

Table 1 shows demographic and psychometric data of the four groups. As can be seen, groups did not differ with respect to age $\left[F(3,26)<1 ; P=0.60 ; \eta_{\mathrm{p}}^{2}=0.07\right]$. Pearson Chi-square Exact tests showed that groups were similar with respect to the proportion of women who smoked $\left[\chi^{2}(3, N=30)=1.04 ; P=0.95\right.$; Cramer's $V=0.16]$, but that women in the repressed and the recovered group were more likely to have received psychiatric treatment related to their alleged CSA history than women in the continuous or control group $\left[\chi^{2}(3, N=30)=24.19 ; \quad P<0.001 ;\right.$ Cramer's $V=0.79]$. Groups also differed in their mean scores on the DES $\left[F(3,26)=10.79 ; P<0.001 ; \eta_{\mathrm{p}}^{2}=0.55\right]$ and the PSS-SR $\left[F(3,26)=3.82 ; P<0.05 ; \eta_{\mathrm{p}}^{2}=0.31\right]$. Follow-up $t$-tests showed that the participants reporting recovered, repressed or continuous CSA memories scored significantly higher on dissociative symptoms (DES) and post-traumatic stress disorder symptoms (PSS-SR) than the control group [all $t$ 's $>2.29$; all $P$ 's $<0.05$ ]. Overall, groups did not differ with respect to current symptoms of depression (BDI) $[F(3,26)=2.05 ; P=0.13$; $\left.\eta_{\mathrm{p}}^{2}=0.19\right]$, but a posteriori $t$-tests indicated that the repressed and continuous CSA groups were more depressed than the control participants [both $t$ 's $>2.36$; both $P$ 's $<0.05$ ].

Table 1

Demographic data, wake-up times, quality of sleep data, and mean ( \pm S.D.) scores of the four groups on measures of dissociation (DES), current depression (BDI), and PTSS symptoms (PSS-SR)

\begin{tabular}{lllll}
\hline & $\begin{array}{l}\text { Recovered } \\
(n=7)\end{array}$ & $\begin{array}{l}\text { Repressed } \\
(n=8)\end{array}$ & $\begin{array}{l}\text { Continuous } \\
(n=6)\end{array}$ & $\begin{array}{l}\text { Control } \\
(n=9)\end{array}$ \\
\hline Age & $40.7(12.6)$ & $43.9(6.7)$ & $36.5(10.5)$ & $43.0(12.2)$ \\
Ratio current & $1 / 6$ & $2 / 6$ & $2 / 4$ & $2 / 7$ \\
$\quad$ smokers & & & & \\
$\quad($ yes/no) & & & & \\
Ratio in & $7 / 0$ & $7 / 1$ & $2 / 4$ & $0 / 9$ \\
$\quad$ psychiatric & & & & \\
$\quad$ treatment & & & & \\
$\quad($ yes/no) & & & & \\
Wake-up time & $07.14 \mathrm{~h}$ & $07.17 \mathrm{~h}$ & $07.35 \mathrm{~h}$ & $07.10 \mathrm{~h}$ \\
Quality of sleep & $58.9(15.9)$ & $55.0(24.0)$ & $50.4(20.9)$ & $69.9(21.6)$ \\
DES $^{\mathrm{b}}$ & $22.2(11.1)$ & $34.4(13.8)$ & $23.1(4.2)$ & $8.7(3.6)$ \\
BDI & $10.1(8.8)$ & $13.5(6.6)$ & $13.2(3.3)$ & $6.7(5.3)$ \\
PSS-SR $^{\mathrm{c}}$ & $14.6(10.8)$ & $20.3(13.4)$ & $14.8(3.2)$ & $5.6(4.3)$ \\
\hline
\end{tabular}

\footnotetext{
${ }^{a}$ Repressed $>$ controls, recovered $>$ controls, and recovered $>$ continuous; $P<0.05$.

${ }^{\mathrm{b}}$ Repressed $>$ controls, recovered $>$ controls, continuous $>$ controls; $P<0.05$ (after Bonferroni correction).

${ }^{\mathrm{c}}$ Repressed $>$ controls; $P<0.05$.
} 


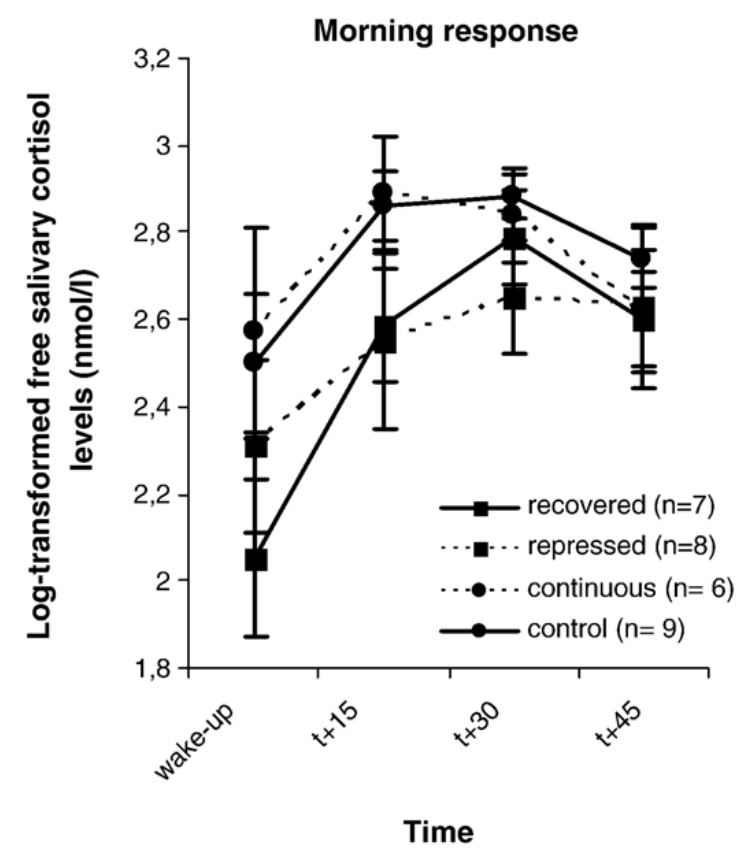

Fig. 1. Morning cortisol rise in participants reporting recovered, repressed, or continuous memories of CSA and control participants without a history of CSA. Individual data points represent average mean values ( \pm S.E.) of 2 sampling days.

\subsection{Wake-up time and quality of sleep}

Table 1 shows wake-up times and quality of sleep data for the four groups. As can be seen, participants in the control group on average tended to wake up $4 \mathrm{~min}, 7 \mathrm{~min}$, and $25 \mathrm{~min}$ earlier than women in the recovered, repressed, or continuous memory group, respectively. Data on subjective sleep quality were missing for one participant in the repressed memory group. Ratings $(\mathrm{M} \pm \mathrm{S}$.D.) of participants' sleep quality averaged over 2 consecutive days did not differ significantly between the 4 groups $[F(3,25)=$ $\left.1.23 ; P=0.32 ; \eta_{\mathrm{p}}^{2}=0.13\right]$.

\subsection{Cortisol responses to awakening ${ }^{l}$}

Clear-cut morning cortisol responses were observed in all groups (see Fig. 1). Accordingly, the repeated measures ANOVA showed a significant main effect of time $\left[F(3,78)=14.95 ; P<0.001 ; \eta_{\mathrm{p}}^{2}=0.37\right]$, reflecting the expected morning rise in cortisol. However, the critical Time $\mathrm{x}$ Group interaction $[F(9,78)=1.20 ; P=0.33$;

\footnotetext{
${ }^{1}$ To control for possible effects of age, time of awakening, current symptoms of PTSD (PSS-SR), and current depression (BDI), the analyses reported in Sections 3.3 and 3.4 were repeated with these factors included as covariates. However, no discrepancies were found between the results with these covariates included and the results reported here.
}

$\left.\eta_{\mathrm{p}}^{2}=0.12\right]$ and main effect of group $[F(3,26)=1.12$; $\left.P=0.36 ; \eta_{\mathrm{p}}^{2}=0.11\right]$ fell short of significance. Likewise, analysis of the AUCi showed that groups did not differ in AUCi in response to awakening $[F(3,26)=0.85 ; P=0.48$; $\left.\eta_{\mathrm{p}}^{2}=0.09\right]$, means being $16.66( \pm 7.05), 10.98( \pm 12.18)$, $8.38( \pm 8.21)$, and $10.73( \pm 10.59)$ for the recovered, repressed, continuous, and control group, respectively. The ACR also did not differ between groups $[F(3,26)=1.18$; $\left.P=0.34 ; \eta_{\mathrm{p}}^{2}=0.12\right]$.

\subsection{Diurnal pattern of cortisol}

Normal diurnal pattern of cortisol secretion was apparent for all 4 groups (see Fig. 2). As expected, the ANOVA showed a main effect of time $F(3,78)=130.30$; $\left.P<0.001 ; \eta_{\mathrm{p}}^{2}=0.84\right]$, with cortisol levels continuously declining over the course of the day. Importantly, no main effect of group $\left[F(3,26)=0.39 ; P=0.76 ; \eta_{\mathrm{p}}^{2}=0.04\right]$ or a Time $\times$ Group interaction $[F(3,78)=0.90 ; P=0.51$; $\left.\eta_{\mathrm{p}}^{2}=0.09\right]$ emerged. In line with this, an ANOVA showed no differences between groups in DAC scores $[F(3,26)=$ $\left.0.40 ; P=0.76 ; \eta_{\mathrm{p}}^{2}=0.04\right]$. Last of all, no group differences were found with respect to diurnal cortisol slopes $(\beta$ 's $)$ $\left[F(3,26)=1.63 ; P=0.21 ; \eta_{\mathrm{p}}^{2}=0.16\right]$.

\subsection{Correlations between AUCi, ACR, DAC, $\beta$ 's and psychometric data}

Correlations between DES, BDI, and PSS-SR scores, on the one hand, and morning cortisol response (i.e., AUCi and ACR) and daily cortisol secretion (i.e., DAC

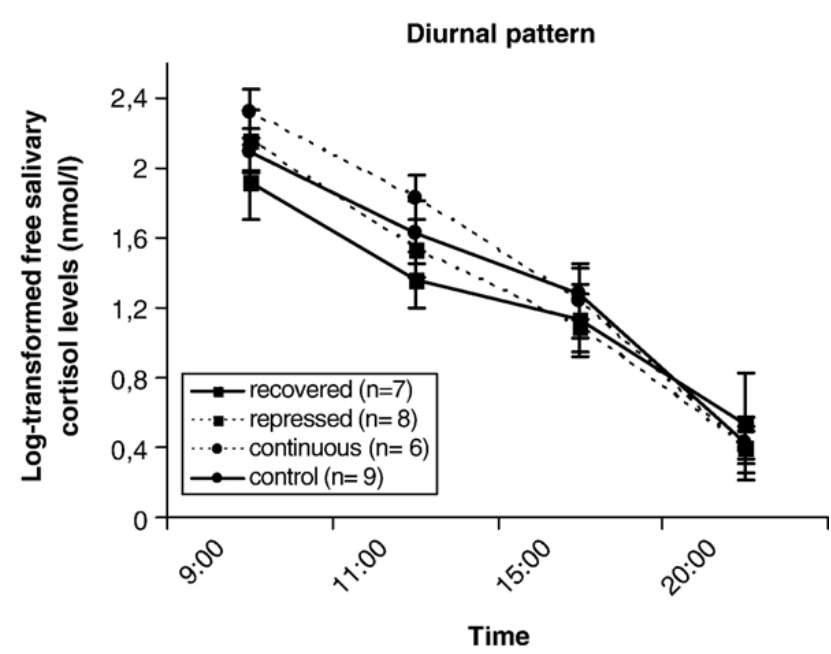

Fig. 2. Circadian rhythm of cortisol secretion for women with recovered, repressed, or continuous CSA memories and women without CSA histories. Data points represent average mean values $( \pm$ S.E.) of 2 sampling days. 
and $\beta$ 's) parameters, on the other, all remained nonsignificant (all $r$ 's $<0.22$; all $P$ 's $>0.23$ ).

\section{Discussion}

Bremner argued that "Modulation of memory function by cortisol and norepinephrine may represent a mechanism of delayed recall of childhood abuse. [...] Long-term dysregulation of these systems may result in chronic changes in the way memories are retrieved in abuse survivors with PTSD. For example, exaggerated cortisol release during stress in PTSD may result in an inhibition of memory retrieval. [...] Both acute and chronic responses of these neurochemical systems to stress need to be considered in order to understand alterations in memory encoding and retrieval that we propose underlie delayed recall of childhood abuse." This is the first study that compared cortisol levels in women with recovered, repressed, or continuous CSA memories to those of women without CSA history. The main results of the present study can be summarised as follows. First, contrary to what one would predict on the basis of theories popular in the recovered memory literature, we found no abnormalities in the cortisol patterns of women who had repressed, recovered, or continuous CSA memories. That is, neither the awakening rise nor the diurnal pattern in cortisol differed between CSA groups and controls, with all four groups showing a straightforward morning response and a typical diurnal rhythm of cortisol secretion. Second, morning responses in terms of AUCi and ACR and daily cortisol secretion (i.e., DAC and $\beta$ 's) were not significantly related to measures of dissociation, current depression, or PTSD symptom severity.

Our psychometric data clearly indicate that the groups who reported CSA memories reported more trauma-related and dissociative symptoms than the control group. For example, on the PSS-SR the repressed memory group scored well above the cut-off point of 15 which, according to Wohlfarth et al. (2003), results in a sensitivity and specificity of . 90 for predicting PSTD. Likewise, PSS-SR scores of the recovered and continuous memory groups came close to this cut-off point. Thus, there is little reason to assume that our CSA memory groups were free of psychiatric symptoms. Nevertheless, we found no association between post-traumatic or dissociative symptoms and cortisol levels. Our failure to obtain a correlation between dissociative symptoms and cortisol levels concurs with a study of Giesbrecht and colleagues (in press). These authors noted that cortisol responses following exposure to a psychosocial stressor were unrelated to measures of dissociation.
Although theories intended to explain delayed recall of CSA memories predict excessive cortisol levels in participants with repressed and recovered memories (e.g., Bremner, 2001), we found no differences in morning response or diurnal cycle of cortisol between women reporting recovered, repressed, or continuous memories of CSA, and women without a history of CSA. Thus, we found no support for the hypothesis that chronic alterations of neurochemical systems (e.g., cortisol) in reaction to trauma exposure can account for delayed recall of CSA memories. Additionally, the present data are at odds with Joseph's (1999) notion that fluctuations in daytime cortisol patterns are a possible hallmark of individuals with recovered memories of CSA.

All in all, our data provide no evidence for the idea that elevated cortisol secretion contributes to the temporary inaccessibility and subsequent recovery of traumatic memories. One could speculate, though, that our recovered memory participants had recovered their memories precisely because their cortisol levels had normalized. While such line of reasoning might make sense in the case of people with recovered CSA memories, it fails to account for the normal cortisol patterns in people reporting repressed CSA memories. Alternatively, there have been case studies suggesting that lowered rather than elevated cortisol levels are responsible for the inaccessibility of memories (e.g., Wolf et al., 2005). But then again, as far as the subsample of people claiming to have repressed their CSA memories is concerned, our data provide no support for this speculation.

Popular theories about the delayed recall of trauma memories also emphasize that chronically elevated cortisol levels due to trauma exposure may serve as a neurobiological pathway to PTSD. However, most studies in this domain (e.g., Yehuda et al., 1990, 1995, 2005; for a comprehensive review, see Yehuda, 2002) have found lowered cortisol levels in PTSD patients. Thus, in line with the present study, research on HPA functioning in PTSD patients seems to implicate that neurobiological models stressing cortisol elevations are not all that compelling.

Our findings suggest that neuroendocrine differences prior to or after trauma exposure are not the sole or even the best candidate to explain the inability to remember the trauma that is said to be characteristic of recovered memories. An alternative explanation is that individuals reporting recovered CSA memories do not exhibit an inability to remember the CSA episode, but rather suffer from subtle cognitive distortions. For example, research has shown that women reporting repressed or recovered memories tend to overestimate prior forgetting (i.e., the 
"forgot-it all-along" effect; see Merckelbach et al., 2006; Geraerts et al., in press). Together with the current findings, these studies (for an excellent review, see McNally, 2003) suggest that cognitive distortions rather than neurochemical alterations following trauma exposure might account for the phenomenal experience of recovered memories.

Several limitations of the current study deserve some comment. One important limitation is that the stringent exclusion criteria (e.g., medication) resulted in a small sample size. Future studies should attempt to replicate these findings using larger sample sizes. Note, however, that the effect sizes seem to indicate that larger samples would yield a similar pattern of results. There is the theoretical possibility that sampling problems, such as non-compliance with the protocol, contributed to our non-significant findings. However, self-reported sampling times showed only small deviations from the planned sampling times. Furthermore, one could question whether self-reported quality of sleep and the resulting non-significant differences between groups on these ratings is sufficiently valid to rule out the possibility that sleep quality confounded the present results. In addition, though it is unlikely that menstrual cycle phase influenced the awakening cortisol responses (e.g., Kudielka and Kirschbaum, 2003), our failure to control for menstrual cycle phase may have confounded the diurnal cortisol values. We also acknowledge that a prospective, within-subject study would be better to investigate HPA axis changes over time, but given the studied population one can see that such an endeavor would be next to impossible. Finally, while participants reported not to have suffered potentially traumatic experiences (other than CSA) in their lives, another measure of life stressors would have been desirable. Also, non-disclosure of other traumatic experiences cannot be ruled out.

In sum, our findings provide no evidence for the idea that cortisol levels are chronically altered in women with recovered, repressed, or continuous CSA memories. As things stand, neurobiological models stressing cortisol dynamics as an important contribution to recovered or repressed memories do not seem to be very promising.

\section{Acknowledgments}

This research was supported by the Netherlands Organization for Scientific Research (NWO) grant 452-02006 awarded to Dr. Marko Jelicic. The authors thank Dr. N. A. Nicolson, Department of Psychiatry and Neuropsychology, Maastricht University (the Netherlands) for helpful comments on an earlier draft of this manuscript, and Dr. J. Sulon, Université de Liège (Belgium) for conducting the cortisol analyses.

\section{References}

Alpert, J.L., Brown, L.S., Courtois, C.A., 1998. Symptomatic clients and memories of childhood sexual abuse: What the trauma and child sexual abuse literature tells us. Psychology, Public Policy, and Law 4, 1052-1067.

Beck, A.T., Ward, C.H., Mendelson, M., Mock, J., Erbaugh, J., 1961. An inventory for measuring depression. Archives of General Psychiatry 4, 561-571.

Beck, A.T., Steer, R.A., Garbin, M.G., 1988. Psychometric properties of the Beck Depression Inventory: Twenty-five years of evaluation. Clinical Psychology Review 8, 77-100.

Bernstein, E.M., Putnam, F.W., 1986. Development, reliability, and validity of a dissociation scale. Journal of Nervous and Mental Disease 174, 727-735.

Bremner, J.D., 2001. A biological model for delayed recall of childhood abuse. Journal of Aggression, Maltreatment and Trauma 4, 165-183.

Bremner, J.D., 2003. Long-term effects of childhood sexual abuse on brain and neurobiology. Child and Adolescent Psychiatric Clinics 12, 271-292.

Bremner, J.D., Krystal, J.H., Charney, D.S., Southwick, S.M., 1996. Neural mechanisms in dissociative amnesia for childhood abuse: Relevance to the current controversy surrounding the "false memory syndrome". American Journal of Psychiatry 153, 71-82 (Suppl).

Bremner, J.D., Vermetten, E., Afzal, N., Vythilingam, M., 2004. Deficits in verbal declarative memory function in women with childhood sexual abuse-related posttraumatic stress disorder. Journal of Nervous and Mental Disease 192, 643-649.

Clow, A., Thorn, L., Evans, P., Hucklebridge, F., 2004. The awakening cortisol response: methodological issues and significance. Stress 7, $29-37$.

Elzinga, B.M., Bakker, A., Bremner, J.D., 2005. Stress-induced cortisol elevations are associated with impaired delayed, but not immediate recall. Psychiatry Research 134, 211-223.

Foa, E.B., Riggs, D.S., Dancu, C.V., Rothbaum, B.O., 1993. Reliability and validity of a brief instrument for assessing posttraumatic stress disorder. Journal of Traumatic Stress 6, 459-473.

Geraerts, E., Smeets, E., Jelicic, M., van Heerden, J., Merckelbach, H., 2005. Fantasy proneness, but not self-reported trauma is related to DRM performance of women reporting recovered memories of childhood sexual abuse. Consciousness and Cognition 14, 602-612.

Geraerts, E., Arnold, M. M., Lindsay, D. S., Merckelbach, H., Jelicic, M., Hauer, B., in press. Forgetting of prior remembering in persons reporting recovered memories of childhood sexual abuse. Psychological Science.

Geraerts, E., Smeets, E., Jelicic, M., Merckelbach, H., van Heerden, J., 2006. Retrieval inhibition of trauma-related words in women reporting repressed or recovered memories of childhood sexual abuse. Behaviour Research and Therapy 44, 1129-1136.

Giesbrecht, T., Smeets, T., Merckelbach, H., Jelicic, M., in press. Depersonalization experiences in undergraduates are related to heightened stress cortisol responses. The Journal of Nervous and Mental Disease.

Gunnar, M.R., Morison, S.J., Chisholm, K., Schuder, M., 2001. Salivary cortisol levels in children adopted from Romanian orphanages. Development and Psychopathology 13, 611-628. 
Howe, M.L., 1998. Individual differences in factors that modulate storage and retrieval of traumatic memories. Development and Psychopathology 10, 681-698.

Joseph, R., 1999. The neurology of traumatic dissociative amnesia: commentary and literature review. Child Abuse and Neglect 23, $715-727$.

Kihlstrom, J. F., in press. Trauma and memory revisited. In: Uttl B., Ohta N., Siegenthaler A. L. (Eds.), Memory and emotions: Interdisciplinary perspectives. New York: Blackwell.

Kudielka, B.M., Kirschbaum, C., 2003. Awakening cortisol responses are influenced by health status and awakening time but not by menstrual cycle phase. Psychoneuroendocrinology 28, 35-47.

Kunz-Ebrecht, S.R., Kirschbaum, C., Marmot, M., Steptoe, A., 2004. Differences in cortisol awakening response on work days and weekends in women and men from the Whitehall II cohort. Psychoneuroendocrinology 29, 516-528.

Loftus, E., 2004. Dispatch from the (un)civil memory wars. Lancet 364, S20-S21.

McNally, R.J., 2003. Remembering Trauma. Belknap Press/Harvard University Press, Cambridge, MA.

Merckelbach, H., Smeets, T., Geraerts, E., Jelicic, M., Bouwen, A., Smeets, E., 2006. I haven't thought about this for years! Dating recent recalls of vivid memories. Applied Cognitive Psychology 20,33-42.

Nicolson, N.A., 2004. Childhood parental loss and cortisol levels in adult men. Psychoneuroendocrinology 29, 1012-1018.

Nicolson, N.A., van Diest, R., 2000. Salivary cortisol patterns in vital exhaustion. Journal of Psychosomatic Research 49, 335-342.

Pope Jr., H.G., Hudson, J.I., Bodkin, J., Oliva, P., 1998. Questionable validity of "dissociative amnesia" in trauma victims: Evidence from prospective studies. British Journal of Psychiatry 172, 210-215.

Pruessner, J.C., Wolf, O.T., Hellhammer, D.H., Buske-Kirschbaum, A., von Auer, K., Jobst, S., Kaspers, F., Kirschbaum, C., 1997. Free cortisol levels after awakening: A reliable biological marker for the assessment of adrenocortical activity. Life Sciences 61, 2539-2549.

Pruessner, J.C., Hellhammer, D.H., Kirschbaum, C., 1999. Burnout, perceived stress, and cortisol responses to awakening. Psychosomatic Medicine 61, 197-204.

Pruessner, J.C., Kirschbaum, C., Meinlschmid, G., Hellhammer, D.H., 2003. Two formulas for computation of the area under the curve represent measures of total hormone concentration versus timedependent change. Psychoneuroendocrinology 28, 916-931.

Roediger III, H.L., Bergman, E.T., 1998. The controversy over recovered memories. Psychology, Public Policy, and Law 4, 1091-1109.

Scheflin, A.W., Brown, D., 1996. Repressed memory or dissociative amnesia: What the science says. Journal of Psychiatry and Law 24, $143-188$
Sephton, S.E., Sapolsky, R.M., Kraemer, H.C., Spiegel, D., 2000 Diurnal cortisol rhythm as a predictor of breast cancer survival. Journal of the National Cancer Institute 92, 994-1000.

Stanton, M.E., Gutierrez, Y.R., Levine, S., 1988. Maternal deprivation potentiates pituitary-adrenal stress responses in infant rats. Behavioral Neuroscience 102, 692-700.

Steptoe, A., Kunz-Ebrecht, S., Owen, N., Feldman, P.J., Willemsen, G., Kirschbaum, C., Marmot, M., 2003. Socioeconomic status and stress-related biological responses over the working day. Psychosomatic Medicine 65, 461-470.

Van IJzendoorn, M.H., Schuengel, C., 1996. The measurement of dissociation in normal and clinical populations: meta-analytic validation of the Dissociative Experiences Scale (DES). Clinical Psychology Review 16, 365-382.

Weissbecker, I., Floyd, A., Dedert, E., Salmon, P., Sephton, S., 2006. Childhood trauma and diurnal cortisol disruption in fibromyalgia syndrome. Psychoneuroendocrinology 31, 312-324.

Wohlfarth, T.D., van den Brink, W., Winkel, F.W., ter Smitten, M., 2003. Screening for posttraumatic stress disorder: An evaluation of two self-report scales among crime victims. Psychological Assessment $15,101-109$.

Wolf, O.T., Fujiwara, E., Luwinski, G., Kirschbaum, C., Markowitsch, H.J., 2005. No morning cortisol response in patients with severe global amnesia. Psychoneuroendocrinology 30, 101-105.

Wüst, S., Federenko, I., Hellhammer, D.H., Kirschbaum, C., 2000a. Genetic factors, perceived chronic stress, and the free cortisol response to awakening. Psychoneuroendocrinology 25, 707-720.

Wüst, S., Wolf, J., Hellhammer, D.H., Federenko, I., Schommer, N., Kirschbaum, C., 2000b. The cortisol awakening response: Normal values and confounds. Noise and Health 7, 77-85.

Yehuda, R., 2002. Post-traumatic stress disorder. New England Journal of Medicine 346, 108-114.

Yehuda, R., Southwick, S.M., Nussbaum, G., Wahby, V., Giller, E.L., Mason, J.W., 1990. Low urinary cortisol excretion in patients with posttraumatic stress disorder. Journal of Nervous Mental Disease 178, 366-369.

Yehuda, R., Kahana, B., Binder Brynes, K., Southwick, S.M., Mason, J.W., Giller, E.L., 1995. Low urinary cortisol excretion in Holocaust survivors with posttraumatic stress disorder. American Journal of Psychiatry 152, 982-986.

Yehuda, R., Golier, J.A., Kaufman, S., 2005. Circadian rhythm of salivary cortisol in Holocaust survivors with and without PTSD. American Journal of Psychiatry 162, 998-1000. 